such patients. However, we would welcome further research data in this area.

\section{P.L.P. Brand* and A. Bush ${ }^{*}$}

*Princess Amalia Children's Clinic, Zwolle, The Netherlands, and "Peadiatric Respiratory Medicine, Royal Brompton Hospital, London, UK.

\section{STATEMENT OF INTEREST}

A statement of interest for P.L.P. Brand can be found at www.erj.ersjournals.com $/ \mathrm{misc} /$ statements.shtml

\section{REFERENCES}

1 Brand PLP, Baraldi E, Bisgaard $\mathrm{H}$, et al. Definition, assessment and treatment of wheezing disorders in preschool children: an evidence-based approach. Eur Respir J 2008; 32: 1096-1110.

2 Lehtinen P, Ruohola A, Vanto T, Vuorinen T, Ruuskanen O, Jartti T. Prednisolone reduces recurrent wheezing after a first wheezing episode associated with rhinovirus infection or eczema. J Allergy Clin Immunol 2007; 119: 570-575.

DOI: $10.1183 / 09031936.00166008$

\title{
Lung function decline in COPD trials
}

\section{To the Editors:}

In his recent editorial, SUISSA [1] has again expressed criticism of the TORCH (Toward a Revolution in Chronic Obstructive Pulmonary Disease (COPD) Health) trial [2]. The focus this time is the analysis of rate of decline in lung function [3], and in particular he questions whether the reduction in rate of decline in forced expiratory volume in one second (FEV1) observed with the active treatments (salmeterol, fluticasone or the combination of both treatments) compared with placebo is due to "regression to the mean" caused by missing data.

Missing data for lung function and exacerbations are unfortunately inevitable in any long-term trial in COPD. SUISSA [1] states that "... measurements were missing so that the pure intent-to-treat analysis was not possible". Such a "pure intentto-treat" analysis of lung function or exacerbation data is not possible for any long-term COPD trial, as this would require complete data.

In fact, the quantity of missing data for lung function in TORCH is similar to the UPLIFT (Understanding Potential Long-term Impacts on Function with Tiotropium) [4] and OPTIMAL [5] trials quoted in the article by SUISSA [1]. In TORCH, 4,857 (79\%) patients provided lung function data at 48 weeks, OPTIMAL had complete 1-yr lung function data for $322(72 \%)$ patients and, in UPLIFT, 4,970 (83\%) patients were included in the rate of decline analysis. To suggest that TORCH is different from either UPLIFT or OPTIMAL in terms of the impact of missing data is misleading.

SUISSA [1] claims that the treatment comparisons for rate of decline in TORCH may be influenced by regression to the mean. Regression to the mean is a phenomenon commonly associated with comparisons where data collected at a given time-point are compared with baseline or historical data. Randomised trials, such as TORCH, where active interventions are compared with placebo, are generally viewed as avoiding this problem, since any regression to the mean should affect all groups equally [6].
The data generated by SuISSA [1] for his "illustration" of the problem are questionable. He has selected only those 322 patients from OPTIMAL who completed the study, in order to make inferences about patients who did not complete (e.g. any patient who died during the OPTIMAL study was not included). The problem is then compounded by the false assumption that only patients with the worst lung function withdrew from the study. Removing those with the worst values on the first visit is not the same as removing those who drop out early. Table 1 shows the actual withdrawal pattern from TORCH compared with that assumed by SUISSA [1].

The SUISSA [1] illustration assumes that the 263 placebo patients with no data beyond baseline all came from the lowest $18 \%$ according to baseline FEV1. In fact, only 75 came from this group and the majority of the subjects with no data beyond baseline had higher FEV1 values. Similarly, for the combination therapy, his assumption is that all 141 patients with no data beyond baseline correspond to the lowest $9 \%$ according to baseline FEV1, while in contrast only 17 patients belonged to this group. The illustration

\begin{tabular}{|c|c|c|c|}
\hline TABLE 1 & \multicolumn{3}{|c|}{$\begin{array}{l}\text { Comparison of actual TORCH data and the } \\
\text { SuISSA [1] illustration }\end{array}$} \\
\hline \multicolumn{2}{|c|}{$\begin{array}{l}\text { Stratification according to } \\
\text { FEV1 at baseline }\end{array}$} & $\begin{array}{l}\text { SuIssA [1] assumed } \\
\text { withdrawals }\end{array}$ & Actual withdrawals \\
\hline \multicolumn{4}{|l|}{ Placebo } \\
\hline Lowest $18 \%$ & & 263 & 75 \\
\hline Highest 82 & & 0 & 188 \\
\hline \multicolumn{4}{|c|}{ Combination therapy } \\
\hline Lowest 919 & & 141 & 17 \\
\hline Highest 9\% & & 0 & 124 \\
\hline
\end{tabular}


in the editorial is therefore questionable, as it does not correspond to the actual TORCH data.

Missing data represent a problem for any statistical analysis of clinical trial data and no statistical method can completely compensate. However, the methods used in the TORCH rate of decline analysis [3] correspond to those currently recommended by leading statistical experts [7] and are based on the same underlying principles as those employed in the statistical analysis of the UPLIFT and other large trials.

The analysis using random coefficient regression accounts for the early dropout in the placebo group, assuming that those who drop out would have progressed in a similar way to those in the placebo arm with similar observed data (baseline and on-treatment FEV1 measurements) who remained in the study. For the analysis to be valid, every observation does not need to be observed for every subject and the analysis does not assume that the measurements were in any way "a random sample". In this model, correlation of intercept and slope of the lines representing the decline in FEV1 is expected and is in fact an intrinsic part of the model; for example, if those with the highest baseline have the greatest decline this would be accounted for. Therefore, the objections of SUISSA [1] to the analysis on these grounds are unfounded.

SUISSA [1] particularly focuses on subjects with data only at baseline and those with no data beyond 24 weeks. These patients provided baseline FEV1 data as well as baseline demographic data that are used as covariates in the analysis. In the primary analysis, we included patients with data from at least one post-treatment time-point and, therefore, the model corrected for any imbalance in the treatment groups in terms of their baseline and first on-treatment FEV1. In response to a suggestion from DECRAMER and MOLENBERGHS [8], we have performed an analysis including subjects with only baseline data [9]. This analysis, which adjusts for differences in baseline values between those with no further data and the remainder, shows very similar results to the previously published analysis [3]. Those patients who discontinued treatment in the TORCH trial may, on average, have more severe disease than those who remained on treatment, but it is reasonable to assume that this will be reflected in their baseline FEV1 and demography, which have been allowed for in these analyses.

In conclusion, the editorial by SUISSA [1] singles out TORCH for criticism with regard to missing data when this is a universal feature of all long-term chronic obstructive pulmonary disease trials. The methods used to analyse rate of decline in TORCH represent current best practice and there is no evident justification for his assertion that the results may be influenced by regression to the mean. The illustration he has provided does not correspond to the actual TORCH data. We therefore stand by our conclusion regarding reduction compared with placebo in rate of decline in forced expiratory volume in one second with salmeterol, fluticasone and the combination of both treatments.

O.N. Keene*, B. Celli", J.A. Anderson*, G.T. Ferguson", C.R. Jenkins ${ }^{+}$, P.W. Jones ${ }^{\S}$, J. Vestbo ${ }^{f}$, K. Knobil* ${ }^{*}$ J.C. Yates ${ }^{*}$ and P.M.A. Calverley**

*GlaxoSmithKline, Uxbridge, ${ }^{\S}$ Dept of Respiratory Medicine, St George's Hospital Medical School, London, ${ }^{\dagger}$ School of
Medicine, Wythenshawe Hospital, Manchester, and ${ }^{* *}$ Dept of Medicine, Clinical Sciences Centre, University Hospital Aintree, Liverpool, UK. "Dept of Pulmonary \& Critical Care, St Elizabeth's Medical Center, Boston, MA, and "Pulmonary Research Institute of Southeast Michigan, Livonia, MI, USA. ${ }^{+}$Dept of Respiratory Medicine, Concord Hospital, Sydney, Australia.

\section{STATEMENT OF INTEREST}

Statements of interest for all authors of this manuscript can be found at www.erj.ersjournals.com/misc/statements.shtml

\section{REFERENCES}

1 Suissa S. Lung function decline in COPD trials: bias from regression to the mean. Eur Respir J 2008; 32: 829-831.

2 Calverley PMA, Anderson JA, Celli B, et al. Salmeterol and fluticasone propionate and survival in chronic obstructive pulmonary disease. N Engl J Med 2007; 356: 775-789.

3 Celli BR, Thomas NE, Anderson JA, et al. Effect of pharmacotherapy on rate of decline of lung function in chronic obstructive pulmonary disease: results from the TORCH study. Am J Respir Crit Care Med 2008; 178: 332-338.

4 Tashkin DP, Celli BR, Senn S, et al. A 4-year trial of tiotropium in chronic obstructive pulmonary diease. $N$ Engl J Med 2008; 359: 1543-1554.

5 Aaron SD, Vandemheen KL, Fergusson D, et al. Tiotropium in combination with placebo, salmeterol, or fluticasonesalmeterol for treatment of chronic obstructive pulmonary disease: a randomized trial. Ann Intern Med 2007; 146: 545555.

6 Barnett AG, van der Pols JC, Dobson AJ. Regression to the mean: what it is and how to deal with it. Int J Epidemiol 2005; 34: 215-220.

7 Molenberghs G, Thijs H, Jansen I, et al. Analyzing incomplete longitudinal clinical trial data. Biostatistics 2004; 5: 445-464.

8 Decramer M, Molenberghs G. Does pharmacotherapy reduce the rate of decline of lung function in COPD? Am J Respir Crit Care Med 2009; 179: 171.

9 Celli B. Does pharmacotherapy reduce the rate of decline of lung function in COPD? Am J Respir Crit Care Med 2009; 179: 171-172.

DOI: $10.1183 / 09031936.00169908$

\section{From the authors:}

I thank KEENE et al. for their comments and this opportunity to clarify the concepts presented in my editorial [1]. First, I am reassured that they agree that the principle of intent-to-treat (or intention-to-treat) analysis is fundamental in order to avoid bias in randomised trials. This is particularly crucial for trials leading to such extensive missing data problem issues that $18 \%$ of placebo patients in TORCH (Toward a Revolution in Chronic Obstructive Pulmonary Disease (COPD) Health) did not have a single measure of forced expiratory volume in one second (FEV1) and that by the end of the trial over $45 \%$ were not having their FEV1 measured [2]. It is questionable whether 